\title{
Measuring eudaimonic and non-eudaimonic goods in the pursuit of the good life: The Riverside Eudaimonia Scale and the Rich \& Sexy Well-Being Scale
}

\author{
Seth Margolis · Eric Schwitzgebel · Daniel J. Ozer · Ramona L. Martinez \\ Sonja Lyubomirsky
}

\begin{abstract}
Well-being science has largely focused on subjective well-being, defined in terms of life satisfaction and positive and negative emotions. However, some philosophical accounts of well-being, like "eudaimonia" accounts, emphasize the attainment of goods, such as having deep social relationships and achieving one's creative potential. We supplement psychological measures of eudaimonia by developing two self-report measures of well-being informed by the philosophical literature. The Riverside Eudaimonia Scale (RES) was designed to measure people's perceptions of their eudaimonic well-being along several dimensions emphasized in the philosophical literature on eudaimonia. The Rich \& Sexy Well-Being Scale (RSWBS) was designed to measure people's perceptions of their attainment of other commonly valued goods that have received less attention in the literature on eudaimonic well-being: sex life, wealth, personal physical beauty, and social status. In three studies, we develop and validate these scales.
\end{abstract}

Keywords: Riverside Eudaimonia Scale; Rich \& Sexy Well-Being Scale; well-being; sex life; wealth; personal physical beauty; social status

\section{Introduction}

When people say they are doing well, what do they mean? They might mean they are in a positive state of mind, or they might mean that they are attaining external goods (e.g., financial and career success). While research has shown that external goods such as money and career success are related to well-being to an extent (e.g., Diener \& Biswas-Diener, 2002; Staw et al., 1994), laypeople tend to overestimate the impact of such external goods on well-being (Aknin et al., 2009; Diener \& Seligman, 2004). Indeed, researchers find that materialism and valuing money, image, and power are negatively related to well-being (Belk, 1984; Csikszentmihalyi, 1999; Sheldon et al., 2004). In light of lay beliefs about how to pursue happiness and the consequential impacts of such beliefs on well-being, it would be scientifically useful to have validated scales that assess the extent to which people believe they have attained the kinds of worldly goods that are associated with external conceptions of "doing well."

In this paper, we offer two such scales. One (the Rich \& Sexy Well-Being Scale) assesses the extent to which people believe they have attained external goods such as wealth, sexual

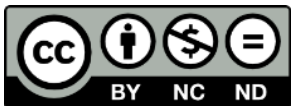

Copyright belongs to the author(s) www.internationaljournalofwellbeing.org 
attractiveness, and power. The other (the Riverside Eudaimonia Scale) assesses the extent to which people believe they have attained "eudaimonic" goods such as positive social relationships and intellectual or artistic achievement. Both scales are focused not on subjective states but on self-ratings of the attainment of these goods. The Eudaimonia scale is informed by philosophical conceptions of human flourishing, while the Rich \& Sexy scale is rooted in psychological work concerning the potentially excessive allure of money, image, and power.

Psychological inquiry into well-being generally falls along two traditions (Deci \& Ryan, 2008; Ryan \& Deci, 2001; see also Keyes et al., 2002): the hedonic approach (emphasizing maximizing positive emotion and minimizing negative emotion; i.e., happiness and subjective well-being traditions) and the eudaimonic approach (emphasizing the fulfillment of human potential; i.e., psychological well-being traditions). Aristotle ( $4^{\text {th }}$ c. BCE/2002) suggested that eudaimonia entailed the attainment of goods related to intellectual and social flourishing, with other contemporary philosophical thinkers following suit (e.g., Haybron 2008; Hurka, 2011; Kraut, 2007; Nussbaum, 2011; Rice, 2013). Philosophers working in this tradition tend to emphasize the attainment of loving relationships, wisdom, creative achievement, meaningful work, and appreciation of beauty.

Most psychological research on well-being examines well-being in terms of subjective mental states. For example, Diener's (1984) conceptualization of subjective well-being-high positive affect, low negative affect, and high life satisfaction - has been central to psychological research on well-being over the past few decades (see Diener et al., 2018, for a review). Although the term "eudaimonia" has been adopted by psychological well-being researchers as well (for example, in the contributions collected in Waterman, 2013, see especially Ryan et al., 2013), it is generally used in a way that emphasizes subjective mental states. The philosophical eudaimonistic tradition emphasizes the attainment of "objective" goods like friendship and meaningful work, thus distinguishing itself from approaches that emphasize subjective affect and satisfaction. Existing eudaimonic measures blend self-reports of subjective experience or satisfaction with self-reports of the attainment of material or psychological goods (Ryff \& Keyes, 1995; Keyes, 2002). Other measures are grounded in the concept of "quality of life" as it applies to health and development policy (Gasper, 2010; Moons et al., 2006). Thus, psychologists presently lack measures of well-being that are specifically constructed with a conception of the attainment of specific outward goods in mind. Previous research also points to psychometric issues with existing eudaimonic measures.

Our aim was to develop two maximally distinct self-report measures of well-being, one focusing on the obtainment of certain desired "high-brow" goods and the other focusing on "lowbrow" goods; see below. Accordingly, we reviewed the philosophical literature on flourishing (e.g., Aristotle, $4^{\text {th }}$ c. BCE/2002; Bishop, 2015; Darwall, 2002; Hurka, 2011; Kraut, 2007; Nussbaum, 2011; Rice, 2013; Sher, 1997), deriving a list of goods that are emphasized, while excluding subjective goods like joy and satisfaction. We also drew on our knowledge of conceptions of "doing well" or flourishing as portrayed in popular culture, including some "low-brow" items, such as wealth and physical beauty. We especially focused on goods that previous psychological research suggest may be overvalued in the pursuit of happiness, such as money, image, and power (Kasser \& Ryan, 1996; Ryan \& Deci, 2000). We then divided this list into five "high-brow" objective goods emphasized by philosophers and five "low-brow" objective goods that are usually omitted from such lists. The former "eudaimonic" list included wisdom, productivity, meaningful relationships, personal growth, and creative achievement. The latter list included wealth, power, fame/popularity, physical beauty, and an active sex life. To maximize the specificity of these lists, we omitted "middle-brow" goods that arguably belong to both lists, such 
as health, security, and autonomy. We also excluded moral goods, such as helping others, because it is tendentious to treat moral attainment as a dimension of personal well-being in the target sense of flourishing "prudentially" - that is, having things go well for you in particular. Our first measure, the Riverside Eudaimonia Scale (RES), was designed to reflect the philosophical conception of eudaimonic flourishing in this "high-brow" sense. The other, the Rich \& Sexy Well-Being Scale (RSWBS), was designed to emphasize instead the attainment of "low-brow" goods.

By "doing well," one might mean that one feels happy and satisfied (subjective well-being), that one is flourishing in distinctively human activities valued by philosophers (eudaimonic wellbeing), or that one has an abundance of wealth, power, beauty, and sex (which we label "rich \& sexy well-being;" i.e., non-eudaimonic well-being). By measuring all three types of flourishing in a way that keeps them theoretically and empirically distinct, we can begin to investigate relationships among these and other constructs (Margolis et al., 2019). We believe that eudaimonic and non-eudaimonic approaches are importantly different. Whether or not "rich \& sexy" goods are conducive or not to sustainable well-being, lay conceptions of their relevance for happiness makes their valid measurement consequentially important. Sheldon and colleagues (2004) find, for instance, that the pursuit of extrinsic goals like wealth, fame, and image, are negatively related to well-being. Borrowing from philosophical wisdom and validating a measure of goods of this kind allows us to further unpack the content and process of the pursuit of the good life.

\subsection{Eudaimonia}

Eudaimonic well-being has two central features: (a) the attainment of certain objective goods, and (b) flourishing with respect to activities constitutive of a human life in its full potential. Eudaimonic well-being, as we intend the phrase, involves actually attaining human excellence, as opposed to merely feeling like one is flourishing. Philosophers in the eudaimonic tradition thus emphasize the attainment of such goods as genuinely loving relationships, practical wisdom, appreciation of beauty, and meaningful creative work (Aristotle, $4^{\text {th }}$ c. BCE/2002; Darwall, 2002; Hurka, 2011; Nussbaum, 2011; Sher, 1997).

Although most psychological research on well-being has focused on subjective well-being, a large body of work also examines eudaimonic well-being (see Ryff, 2014, for a review). Measurement issues are a central concern in this research. It is difficult to determine whether someone has actually attained goods like wisdom and appreciation of beauty. Self-report methods, despite their limitations, are commonly used in eudaimonic research.

Most eudaimonic research uses one of three scales: The Psychological Well-Being Scale (PWBS; Ryff \& Keyes, 1995), the Mental Health Continuum (MHC; Keyes, 2002), or the Questionnaire for Eudaimonic Well-Being (QEWB; Waterman et al., 2010). Other measures are sometimes considered eudaimonic, but most of these measures were designed to assess something other than eudaimonia in the context of the attainment of specific goods (see Sheldon, 2018). Below we review these measures and evaluate whether this philosophical notion of wellbeing is represented in the measures' content.

Ryff (1989) surveyed the psychological literature and proposed the following six dimensions of psychological well-being: self-acceptance, positive relations with others, autonomy, environmental mastery, purpose in life, and personal growth. This definition of psychological well-being is often equated with eudaimonia (Proctor \& Tweed, 2016). Ryff and Keyes (1995) introduced a measure of psychological well-being that assesses each of the six dimensions of psychological well-being with three items (PWBS). Each 3-item subscale was found to have poor 
internal consistency (ranging from .17 to .68), and the intended six-factor model fit observed data marginally better than a one-factor model (van Dierendonck, 2004). Ryff's six-factor model seems also to fit poorly with 42-item, 54-item, and 84-item, and 120-item versions of the PWBS (Abbott et al., 2006; Kafka \& Kozma, 2002; van Dierendonck, 2004).

Furthermore, the surface content of the PWBS does not target eudaimonic well-being in a non-experiential sense and omits some goods central to philosophical accounts. Some items ask for self-ratings of components of eudaimonic flourishing, such as loving ("I have not experienced many warm and trusting relationship with others"; reverse scored) and learning ("For me, life has been a continuous process of learning, changing, and growth"). However, the PWBS lacks self-ratings of intellectual or creative achievement. Also, some items appear to measure subjective well-being, including life satisfaction ("When I look at the story of my life, I am pleased with how things have turned out") and negative emotion ("The demands of everyday life often get me down"; reverse scored). Other items overlap with types of flourishing we aim to capture with our new Rich \& Sexy Well-Being Scale (e.g., "I generally do a good job of taking care of my personal finances and affairs"). Although philosophical conceptions of eudaimonic flourishing sometimes include life satisfaction, financial competence, and minimal negative emotion, these goods are not distinctive of eudaimonic flourishing, which pertains to the attainment of nonexperiential goods. Inclusion of such items in the PWBS impairs its ability to specifically target eudaimonic well-being. As its name suggests, the Psychological Well-Being Scale may measure psychological well-being in general as opposed to eudaimonia particularly.

Extending Ryff's (1989) work, Keyes (2002) created the Mental Health Continuum (MHC). This measure assesses emotional, psychological, and social well-being. The social component is unique to the MHC, whereas the first two components borrow from other measures. The MHC includes three items to assess emotional (i.e., subjective) well-being, with one item for each of Diener's (1984) components. Six items of the MHC are used to measure each of Ryff's six components of psychological well-being with one scale. Lastly, Keyes developed five new items, with each one measuring a different aspect of social well-being. Subsequent research has supported the three-factor structure of the MHC (De Bruin \& Du Plessis, 2015; Franken et al., 2018; Jovanovic, 2015; Lamers et al., 2011). In addition, the measure seems to have suitable reliability (e.g., Cronbach's alphas above .9) and construct validity (Franken et al., 2018; Keyes et al., 2008).

However, like the PWBS, the MHC contains not only items that target objective flourishing but also more subjective items like, "During the [past month], how often did you feel ... "happy" and "satisfied with life." Furthermore, the surface content of some items is not straightforwardly related to eudaimonic flourishing. For example, "During the [past month], how often did you feel"..."that people are basically good" might capture something like optimism and positive sociality, but some philosophers argue that wisdom requires rejecting the belief that people are basically good (Hobbes 1651/1996; Schopenhauer 1851/2007; Xunzi, 3 ${ }^{\text {rd }}$ c BCE/2014; for discussion, see Schwitzgebel, 2007). As with the PWBS, the name of the MHC accurately suggests its broad theoretical target-namely, mental health in general, not eudaimonic flourishing in particular. Diener and colleagues' (2010) Flourishing Scale-conceptualized as a measure of "social-psychological prosperity" - similarly captures a mix of subjective feelings ("I am engaged and interested in my daily activities"), optimism, and elements of eudaimonic flourishing, as well as ethical engagement ("I actively contribute to the happiness and well-being of others").

Lastly, Waterman and his colleagues (2010) developed a 21-item eudaimonia measure. Initial testing of the Questionnaire for Eudaimonic Well Being (QEWB) provided good reliability and validity evidence (Schutte et al., 2013; Waterman et al., 2010). The scale's items are designed to 
assess self-discovery, perceived development of one's best potentials, a sense of purpose and meaning in life, intense involvement in activities, investment of significant effort, and enjoyment of activities as personally expressive. Although the authors of the scale argue the QEWB is unidimensional, they used a parceling approach that may hide other factors. Other researchers have found that three-factor or four-factor solutions create the most interpretable solution (Schutte et al., 2013). Thus, there appears to be a discrepancy between the number of constructs the scale supposedly measures (6) and the number of factors the scale contains (3 or 4 ).

For our purposes, the content of the QEWB is too narrow. Most of the QEWB's 20 items appear to target meaning in life and being invested in personally worthwhile activities. No items concern love or meaningful personal relationships, and no items directly concern intellectual or artistic attainment (apart from self-knowledge). The QEWB thus appears to target one important aspect of eudaimonic flourishing rather than a broad selection of eudaimonic goods.

In light of these concerns, we sought to design an improved measure of eudaimonia. In addition, we aimed to measure eudaimonia reliably with just a few items. We call this new scale the Riverside Eudaimonia Scale (RES).

\subsection{Non-eudaimonic attainments}

Attainment-oriented approaches to well-being are not all eudaimonic. In popular culture and some philosophical traditions, the good life is sometimes conceived in terms of goods like wealth, beauty, fame, career success, and long life (Homer, 8th c. BCE/1951; The LOX, 1998; the Yangist chapters of the Annals of Lü Buwei [Knoblock \& Riegel, trans., 3rd c. BCE/2000]). Philosophical theories with an objective component, such as those of Nussbaum (2011), Bishop (2015), and even Aristotle ( $4^{\text {th }}$ C. BCE/2002), also often include such goods, although typically these goods receive less emphasis. As discussed above, psychological research suggests that people tend to overvalue goods of this sort in the pursuit of happiness (Aknin et al., 2009; Belk, 1984; Csikszentmihalyi, 1999; Kasser \& Ryan, 1996).

To our knowledge, no existing measure of well-being aims to capture this type of "success." Thus, we sought to develop a new measure focusing distinctively on a broad range of goods that might be regarded as part of "doing well" or as part of a good, enviable life, but which tend to be downplayed in traditional eudaimonic theories. Based on our sense of cultural plausibility and our knowledge of the psychological literature on external goods that may be overvalued in the pursuit of happiness, we targeted wealth, fame/popularity, beauty, power, and sex. We call this new measure the Rich \& Sexy Well-Being Scale (RSWBS). Thus, the RES and RSWBS each target not flourishing overall but more contrasting forms of flourishing, which, to phrase a bit cartoonishly, reflect the vision of the high-minded philosopher on the one hand and the Las Vegas-style partier on the other.

We anticipated that the pursuit and attainment of "rich \& sexy" goods might correlate differently with respondents' values and personality traits than would the pursuit and attainment of eudaimonic goods. In particular, because narcissism, Machiavellianism, and psychopathy all involve manipulativeness in service of selfish ends, we expected these Dark Triad traits to correlate with the RSWBS. We also expected that the RES would correlate with the Big Five personality traits in a manner similar to that of most standard measures of well-being (i.e., highest correlations with extraversion and negative emotionality, lower correlations with agreeableness and conscientiousness and near-zero correlations with open-mindedness; Steel et al., 2008). However, because the pursuit and attainment of "rich \& sexy" goods is generally not highly related to subjective well-being, we anticipated that correlations between RSWBS and Big Five traits might not show the same pattern. Finally, we anticipated that the RSWBS and RES 
might correlate differently with values (as measured by the Schwartz Values Survey; Schwartz, 1992). Given that both the RSWBS and the RES measure self-rated achievement, we anticipated correlations of both with achievement-related values (self-direction, stimulation, and achievement). Because standard measures of well-being find correlations between well-being and valuing moral goods (Aknin et al., 2012; King \& Napa, 1998), we anticipated the RES would correlate with valuing universalism and benevolence. However, due to the unusual focus of the RSWBS on external goods such as sex, money, and power, we anticipated it might correlate instead with valuing hedonism and power.

\subsection{Present studies}

We conducted three studies to develop and validate the RES and the RSWBS. We investigated the factor structure and reliability of these two new measures, and we explored their validity by correlating them with 1) other well-being measures to demonstrate discriminant validity and 2) personality traits and demographic characteristics to provide evidence of construct validity.

To establish discriminant validity, we report disattenuated correlations. These correlations are adjusted upwards based on the reliability of each measure and approximate correlations between latent variables in a structural equation modeling approach. Specifically, a correlation is disattenuated by dividing the original correlation by the square-root of the product of the reliability coefficients of each measure. Because the reliability coefficients are typically less than unity, the denominator will be less than unity, rendering a disattenuated correlation greater than the original correlation. Disattenuated correlations below unity demonstrate differences in the underlying constructs being measured. By contrast, typical attenuated correlations may show evidence of discriminant validity when, in reality, the same construct is being measured with poor reliability. To ensure that our results were not a result of imperfect reliability, we disattenuate our correlations (with $p$-values based on the attenuated correlations).

These three studies draw from data that were also used to develop and validate the Riverside Life Satisfaction Scale (Margolis et al., 2018) and measures of desire fulfillment and desire satisfaction (Margolis et al., 2019). Materials, data, and $\mathrm{R}$ code for this project are available at https://osf.io/n2pw8/?view_only=c376721072e04772890c13fa85090375.

Based on previous theory and research, we expected the following patterns of correlations:

- The RES will correlate highly with other well-being measures.

- The RSWBS will correlate less well than the RES with other well-being measures.

- The RES will correlate with the Big Five in the same manner as most well-being measures.

- The RSWBS will not correlate with the Big Five in the pattern typical of other well-being measures.

- The RES will correlate negatively with the Dark Triad traits.

- The RSWBS will correlate less negatively, or perhaps even positively, with Dark Triad traits.

- Both the RES and the RSWBS will be associated with valuing self-direction, stimulation, and achievement as measured by the Schwartz Values Survey. The RES but not the RSWBS will be associated with valuing universalism and benevolence. The RSWBS but not the RES will be associated with valuing hedonism and power.

Our hypotheses involving the RSWBS are somewhat more tentative relative to those involving the RES. Given that there are no extant validated measures of non-eudaimonic well-being, we are exploring its relationships with other relevant constructs. 


\section{Study 1}

\subsection{Method}

\subsubsection{Participants}

We aimed to recruit approximately 500 participants to ensure a sample size that would provide a high degree of confidence in individual factor loadings, which were used for item selection. The participants $(N=504)$ were recruited from Prolific Academic ${ }^{\mathrm{TM}}$ online panel. We only included participants who spoke English as their first language and did not originate from the U.S. (A U.S. holiday fell between our two assessments, which might have affected our test-retest reliabilities.) Most participants were from the U.K. (79\%) and Caucasian (82\%). Half (51\%) were female, with ages ranging from 18 to 67 years old $(M=35.1, S D=12.0)$. Half $(52 \%)$ of our sample were in a relationship. Their median education was an undergraduate degree, and median household income was $£ 30,000-£ 39,999$.

\subsubsection{Procedure}

Following consent, participants completed several questionnaires and were then compensated $£ 5$. Next, we asked participants to complete the same set of questionnaires 2 weeks later. We recruited 200 participants out of the original sample of 504, but our final sample size was 194 after removing people who did not respond to any items.

\subsubsection{Materials}

The first assessment included the measures described below. The assessment also included additional measures unrelated to the current project.

Participants rated their agreement with five items reflecting a broad range of types of eudaimonia. These items were chosen to reflect the five high-brow goods commonly mentioned in philosophical eudaimonic theories. Rather than creating a large number of items to be reduced in scale development, we carefully constructed the five items to precisely reflect the five target aspects of objective flourishing. One item (adapted from the PWBS) concerned learning and growth. Another targeted meaningful productivity, and a third targeted personal relationships. Wisdom could not be queried directly, as reporting "I am wise" seemed likely to produce paradoxical responses. Therefore, we developed the item, "I know what is really important in life." Finally, we aimed to measure achievement without committing to a narrow view and referred to several types of achievement: "I have realized my creative, artistic, intellectual, or athletic potential." These items were rated on a 7-point Likert scale. See Table S1 of the supplement for a full list of items.

Next, we developed 51 items designed to assess the five potential aspects of non-eudaimonic well-being: the frequency and quality of sex, personal wealth, personal beauty, social image, and social power. See Table S3 for a full list of items. Participants rated their agreement with each item on a 7-point Likert scale.

We measured positive and negative affect with the Affect-Adjective Scale (Diener \& Emmons, 1984). This measure asks participants to rate the extent to which they have felt specific emotions over the past week on a 7-point Likert scale. We added three low-arousal items ("peaceful/serene," "dull/bored," and "relaxed/calm") to the 7-item scale to balance the scale with high and low arousal emotions (Margolis et al., 2018). We computed affect balance scores by reverse scoring negative affect items and then averaging all affect items. McDonald's $\omega_{t}$ (McDonald, 1999) for affect balance, positive affect, and negative affect, were .93, .93, and .87, respectively. 
Participants completed the Riverside Life Satisfaction Scale (RLSS; Margolis et al., 2018). This measure includes three direct and three indirect items regarding life satisfaction. Participants rated these items on a 7-point Likert scale and $\omega_{t}$ equaled .93. The RLSS correlates very highly (disattenuated $r=.96-.97$ ) with the well-known Satisfaction With Life Scale (Diener, et al., 1985), but its surface content maps onto a broader philosophical conception of life satisfaction (Margolis et al., 2018).

We administered the Subjective Happiness Scale (SHS; Lyubomirsky \& Lepper, 1999), which asks participants about their happiness levels. All four items of this measure use a 7-point Likert scale and the measure had an $\omega_{t}$ of .90 .

Participants completed the 18-item version of the Psychological Well-Being Scale (Ryff \& Keyes, 1995), which includes six subscales: autonomy, environmental mastery, personal growth, positive relations with others, purpose in life, and self-acceptance. Items were rated on a 6-point Likert scale. McDonald's $\omega_{t}$ s ranged from .50 to .89 across the six subscales. When all items were averaged to create an overall score of psychological well-being, $\omega_{t}$ equaled 85 .

We measured the traits of Machiavellianism, psychopathy, and narcissism (i.e., The Dark Triad) with The Dirty Dozen (Jonason \& Webster, 2010). This measure includes 12 items on a 7point Likert scale. McDonald's $\omega_{t}$ s for Machiavellianism, psychopathy, and narcissism were .80 , .79 , and .81 , respectively.

Participants completed the 60-item Big Five Inventory-2 (i.e., BFI-2; Soto \& John, 2017a), which measures five traits with three facets each. Each facet is assessed with four items that use a 5-point Likert scale. McDonald's $\omega_{t}$ s ranged from .82 to .92 for the traits and .70 to .85 for the facets.

We obtained demographic information about our participants from Prolific Academic ${ }^{\mathrm{TM}}$. We used the following variables: age, sex, education, relationship, personal income, and household income.

\subsubsection{Missing data}

Approximately $17 \%$ of demographic data were missing. No data were imputed for these variables. $0.1 \%$ of data on psychological measures were missing. We imputed values with R's mice package using predictive mean matching with five iterations (Rubin, 1986; Little, 1988; Schenker \& Taylor, 1996).

\subsection{Results}

\subsubsection{Eudaimonia items}

To assess the structure of our eudaimonia items, we performed exploratory factor analyses. In these analyses, we considered our items to be ordinal, due to their non-normal distributions (see Figure S1). Thus, we used the polychoric correlation matrix and weighted least squares estimation. The extracted eigenvalues $(2.81,0.71,0.60,0.55,0.33)$ suggested the items reflected one latent construct. This general factor explained $46 \%$ of the shared variance among the items. When we extracted a second factor, an additional $10 \%$ of the shared variance could be explained. The small increase in explained variance and pattern of eigenvalues suggested our eudaimonia items were unidimensional.

In addition, we performed confirmatory factor analyses (CFA). We used diagonally weighted least squares estimation and a mean- and variance- adjusted $\chi^{2}$ because our items were treated as ordinal. A one-factor CFA fit the eudaimonia items well $\left(\chi^{2}(5)=361, \mathrm{CFI}=.978, \mathrm{TLI}=.957\right.$, RMSEA $=.111,90 \%$ CI $[.079, .147]$, SRMR $=.038$; see Table S1 for factor loadings). The RMSEA of 
this and other models may indicate worse fit than other fit statistics, because RMSEA is positively biased in models with low degrees of freedom (Kenny et al., 2014).

To assess internal consistency, we examined the average inter-item correlation and $\omega_{t}$, which were .40 and .77, respectively. Another measure of reliability, the 2-week test-retest correlation, was $.75(95 \% \mathrm{CI}=[.38, .81])$.

\subsubsection{Rich $\mathcal{E}$ sexy well-being items}

We investigated the structure of the RSWBS items, again considering the items to be ordinal due to their non-normal distributions (see Figure S2). Using a scree test, the first several eigenvalues $(17.28,3.89,3.44,2.67,2.14,1.58,1.23,1.06,1.03)$ suggest that these items form three to six factors. We conducted exploratory factor analyses with three, four, five, and six factors extracted (with exploratory bifactor analyses showing a similar pattern of results). The four-factor solution, where image and power items had the strongest loadings on one factor (which we label "status") led to the most interpretable factors. See Table S3 for factor loadings from the exploratory factor analysis with four factors and item-total correlations between each item and its subscale.

From the information in Table S3 and item content, we selected four items from each of the four subscales to be included in our RSWBS measure. We conducted a confirmatory factor analysis with these items to assess how well a four-factor model fit the items without crossloadings (Table S2). We found that a four-factor model fit the items well $\left(\chi^{2}(98)=379.6, \mathrm{CFI}=\right.$ $.970, \mathrm{TLI}=.964, \mathrm{RMSEA}=.076,90 \% \mathrm{CI}[.068, .084]$, SRMR $=.051)$. A confirmatory bifactor model with four specific factors also fit the items well $\left(\chi^{2}(88)=272.9, \mathrm{CFI}=.980\right.$, TLI $=.973$, RMSEA $=$ $.065,90 \%$ CI $[.056, .073]$, SRMR $=.045)$.

We examined the internal consistency of the overall RSWBS and each subscale with $\omega_{t}$ (overall RSWBS $=.87$; subscales Sex $=.88$, Wealth $=.80$, Beauty $=.83$, and Status $=.81$ ) and the average inter-item correlation (overall RSWBS $=.30$; subscales Sex $=.62$, Wealth $=.49$, Beauty $=$ .53 , and Status $=.53$ ). The 2 -week test-retest correlations match the $\omega_{t}$ s well (overall RSWBS $=.88$; subscales Sex $=.86$, Wealth $=.78$, Beauty $=.84$, and Status $=.87$ ).

\subsubsection{Associations between the RES and RSWBS and other measures}

Table S5 presents the correlations between the RES and the RSWBS, and demographic variables. Notably, women, highly educated respondents, and respondents in relationships reported higher scores on the RES. Similarly, education and relationship status, as well as income, were positively associated with the RSWBS. Expectedly, the Sex subscale of the RSWBS was positively correlated with relationship status, and the Wealth subscale was positively correlated with income.

Table S4 displays the correlations between the RES and RSWBS, and other psychological constructs. As expected, although the RSWBS correlated with other measures of well-being ( $r^{\prime} \mathrm{s}$ .47-.57 [all reported $r^{\prime}$ s are disattenuated]), the RES correlated more highly (.57 - .88), suggesting that the RES is more closely related to subjective well-being and psychological well-being. The RSWBS and RES correlated at $r=.58$, indicating a substantial relationship. The RES correlated negatively with Dark Triad psychopathy, whereas the RSWBS showed no relationship with psychopathy. Conversely, the RSWBS was positively correlated with Dark Triad Machiavellianism and narcissism, while the RES showed no relationship. The RES showed the expected correlations with Big Five traits, typical of well-being measures. As expected, the RSWBS showed a different pattern, with much lower correlations with agreeableness and conscientiousness. Although open-mindedness is not usually related to measures of subjective well-being (Steel, Schmidt, \& Shultz, 2008), it was related to our objective well-being measures: $r$ $=.25$ for the RSWBS and a strikingly large $r=.52$ for the RES. 


\section{Study 2}

In Study 1, we developed measures of eudaimonia and rich \& sexy well-being. In addition, we examined the correlations of these measures with other psychological measures and demographic characteristics to establish construct validity. In Study 2, we aimed to replicate these correlations using only the final set of RSWBS items. We also added a weekly affect measure to examine whether a more mutable measure of affect correlates as strongly with our new measures as do trait-like measures. Finally, we added measures of socially desirable responding and demand characteristics.

\subsection{Method}

\subsubsection{Participants}

We aimed to recruit approximately 300 participants because we were primarily interested in correlations, which stabilize around sample sizes of 250 (Schönbrodt \& Perugini, 2013). We recruited participants $(N=303)$ from Prolific Academic ${ }^{\mathrm{TM}}$. As in Study 1 , only those who spoke English as their first language were included. Approximately half (45\%) were female, and they were mostly from the United States (69\%) and White (73\%). Participants ranged from 18 to 70 years old $(M=31.9, S D=11.6)$. Approximately a third $(37 \%)$ were in a relationship, and the median education level was an undergraduate degree. The median household income was $£ 40,000-£ 49,999$.

\subsubsection{Procedure}

Following consent, participants completed several questionnaires and were compensated $£ 4$.

\subsubsection{Materials}

Participants completed all of the measures listed below. First, participants rated their agreement with the five eudaimonia items used in Study 1 using a 7-point Likert scale. McDonald's $\omega_{t}$ equaled .78. They then completed the 16 RSWBS items selected in Study 1 using a 7-point Likert scale including subscales for Sex, Wealth, Beauty, and Status. McDonald's $\omega_{t}$ equaled .90 for the overall scale and $.91, .88, .90$, and .87 for each of the subscales, respectively.

Participants completed the RLSS (Margolis et al., 2018), SHS (Lyubomirsky \& Lepper, 1999), PWBS (Ryff \& Keyes, 1995), Dirty Dozen (Jonason \& Webster, 2010), and BFI-2 (Soto \& John, 2017a). For $\omega_{t} \mathrm{~s}$ values for these scales, see Table $\mathrm{S6}$.

To measure affect, we administered the same 12 items used in Study 1 . However, we measured both general and weekly affect using six composite variables: general affect balance, weekly affect balance, general positive affect, weekly positive affect, general negative affect, and weekly negative affect. McDonald's $\omega_{t}$ s ranged from .89 to .93 for these composites.

Participants completed a 16-item version of the Balanced Inventory of Desirable Responding (Hart et al., 2015). Items such as "I never regret my decisions" and "I am a completely rational person" were rated on a 7-point Likert scale and had a $\omega_{t}$ of .82 .

To assess demand characteristics, we administered the Perceived Awareness of the Research Hypothesis Scale (Rubin, 2016), which asks participants to rate how confident they are that they have identified our research hypotheses. This four-item scale uses a 7-point Likert scale and $\omega t$ equaled .91.

Prolific Academic ${ }^{\mathrm{TM}}$ provided the same demographic information for our participants as in Study 1. 


\subsubsection{Missing data}

Psychological measures had a missingness rate of $0.2 \%$ and were imputed using predictive mean matching with five iterations. Demographic variables were missing at a rate of $15 \%$, and no data were imputed.

\subsection{Results}

\subsubsection{Confirmatory factor analyses}

We conducted a one-factor CFA with diagonally weighted least squares estimation and a meanand variance- adjusted $\chi^{2}$ with the eudaimonia items. This model fit well $\left(\chi^{2}(5)=19.6, \mathrm{CFI}=.982\right.$, $\mathrm{TLI}=.965, \mathrm{RMSEA}=.098,90 \%$ CI $[.055, .146]$, SRMR $=.037)$. See Table S1 for factor loadings.

We conducted confirmatory factor analyses with the RSWBS items, again treating the items as ordinal. A four-factor model fit the items well $\left(\chi^{2}(98)=243.2, \mathrm{CFI}=.985, \mathrm{TLI}=.982, \mathrm{RMSEA}=\right.$ $.070,90 \%$ CI $[.059, .081]$, SRMR $=.047)$. See Table S2 for standardized factor loadings. A confirmatory bifactor model with four specific factors also fit the items well $\left(\chi^{2}(88)=185.6, \mathrm{CFI}=\right.$ $.990, \mathrm{TLI}=.986, \mathrm{RMSEA}=.061,90 \%$ CI $[.048, .073], \mathrm{SRMR}=.046)$.

\subsubsection{Associations between the RES and RSWBS and other measures}

Table S5 provides correlations between the RES and the RSWBS and demographic variables. These correlations were similar to those in Study 1. One of the largest differences between the two sets of correlations is that only Study 2 found a positive significant correlation between the RES and personal income (Stieger test of difference between correlations $p=.04$ ).

See Table S6 for correlations between the RES and RSWBS and other psychological constructs. As in Study 1, the RES correlated more highly with other well-being measures (disattenuated r's $=.64-.91)$ than did the RSWBS (.48-.56), and the two new measures correlated with each other at about $\mathrm{r}=.5 .^{1}$ Also as in Study 1 , the RES correlated negatively with psychopathy, and the RSWBS correlated positively with Machiavellianism and narcissism. We also replicated the Study 1 patterns concerning the Big Five personality traits.

Socially desirable responding correlated more strongly with the RES than with the RSWBS (Steiger test of difference between correlations $p<.001$ ), perhaps indicating that people would rather present themselves as high in eudaimonia than high in rich \& sexy well-being. ${ }^{2}$ Lastly, demand characteristics may have impacted the RSWBS more than the RES scores (Stieger test of difference between correlations $p=.01$ ), although we are uncertain why this would be so.

\footnotetext{
${ }^{1}$ The correlations between the RES and life satisfaction and between the RSWBS and life satisfaction are significantly different $(p<.01)$. Likewise, these correlations are significantly different for happiness $(p=.02)$ and psychological wellbeing $(p<.01)$.

${ }^{2}$ We found that socially desirable responding does partially explain the correlation between our scales and other wellbeing constructs of interest, but only modestly. Specifically, we found that the RES was significantly correlated with life satisfaction $(r=.73)$, happiness $(r=.69)$, and psychological well-being $(r=.91)$. After controlling for socially desirable responding, we find that these correlations are smaller, but still significant and in the same direction. Specifically, the RES is significantly correlated with the following well-being variables, controlling for socially desirable responding: life satisfaction $(r=.58)$, happiness $(r=.53)$, and psychological well-being $(r=.70)$.

Similarly, we found that the RSWBS is significantly correlated with life satisfaction $(r=.53)$, happiness $(r=.51)$, and psychological well-being $(r=.56)$. After controlling for socially desirable responding, these correlations become modestly smaller. Specifically, the RSWBS is significantly correlated with the following well-being variables, controlling for socially desirable responding: life satisfaction $(r=.48)$, happiness $(r=.45)$, and psychological well-being $(r=.49)$.
} 


\section{Study 3}

Study 2 replicated Study 1 by reproducing its factor analyses and correlations. Study 2 also extended Study 1 by correlating the RES and the RSWBS with weekly affect, socially desirable responding, and demand characteristics. Study 3 aimed to replicate many of the results of Study 2. Additionally, we tested correlations between values of the Schwartz Values Survey and the RES and RSWBS. We hypothesized that people with different values might seek these different types of well-being. In particular, we expected 1) that both forms of well-being would be associated with valuing the self-direction, stimulation, and achievement, 2) that the RES but not the RSWBS would be associated with valuing universalism and benevolence, and 3) the RSWBS but not the RES would be associated with valuing hedonism and power.

\subsection{Method}

\subsubsection{Participants}

We aimed to recruit approximately 400 participants because we expected that correlations with values might be modest. We again recruited participants $(N=406)$ from Prolific Academic ${ }^{\mathrm{TM}}$ and only included those who spoke English as a first language. Participants were mostly from the U.K. (57\%) and White (78\%). More than half (58\%) were female, ranging in age from 18 to 70 ( $M$ $=36.3, S D=11.8)$. A majority $(62 \%)$ of participants were in a relationship, and their median education level was college/A levels. The median household income was $£ 30,000$ - $£ 39,999$.

\subsubsection{Procedure}

Following consent, participants completed a series of measures and then received $£ 2.5$ for completing the survey.

\subsubsection{Materials}

All the measures described below were administered to participants.

As in Study 2, participants completed the RES $\left(\omega_{t}=.79\right)$ and the RSWBS ( $\omega_{t} \mathrm{~s}=.90$ [Overall], .89 [Sex], .83 [Wealth], .90 [Beauty], and .83 [Status], the RLSS $\left(\omega_{t}=.91\right.$; Margolis et al., 2018), the Affect-Adjective Scale ( $\omega_{t} \mathrm{~S}=.92$ [affect balance], .92 [positive affect], and .89 [negative affect]) and the Balanced Inventory of Desirable Responding $\left(\omega_{t}=.83\right.$, Hart et al., 2015).

Participants completed the BFI-2 Extra-Short (Soto \& John, 2017b). Each trait is measured with three items on a 5-point Likert scale. McDonald's $\omega_{t s}$ ranged from .58 to .80 for the traits.

We administered the Schwartz Values Survey (Schwartz, 1992), which asks participants to rate the extent to which each of 58 values is "a guiding principle in [their lives]" on a scale ranging from -1 (opposed to my values) to 7 (of supreme importance). Items included "social power (control over others, dominance)" and "pleasure (gratification of desires)." The 58 values were scored into 10 value subscales (see list of 10 values in Table S7) with low $\omega_{t}$ s ranging from .31 to .57 .

Prolific Academic ${ }^{\mathrm{TM}}$ provided the same demographic information for our participants as in Studies 1 and 2.

\subsubsection{Missing data}

Demographic variables were missing at a rate of $10 \%$, and no data were imputed. Other measures featured a missingness rate of $0.6 \%$ and were imputed using predictive mean matching with five iterations. 


\subsection{Results}

\subsubsection{Confirmatory factor analyses}

We conducted a one-factor CFA with the RES items, which were treated as ordinal. Thus, we used diagonally weighted least squares estimation and a mean- and variance-adjusted $\chi^{2}$. This model did not fit very well $\left(\chi^{2}(5)=84.3, \mathrm{CFI}=.936\right.$, TLI $=.871, \mathrm{RMSEA}=.198,90 \%$ CI [.162, .236], SRMR $=.067)$. However, if the errors of items 3 and 4 are allowed to correlate, the model fits well $\left(\chi^{2}(4)=17.3, \mathrm{CFI}=.989, \mathrm{TLI}=.973, \mathrm{RMSEA}=.091,90 \% \mathrm{CI}[.050, .136]\right.$, SRMR $\left.=.032\right)$. This model has slightly different factor loadings than a model without correlated errors (loadings $=.71, .89$, $.52, .58, .62)$. See Table S1 for factor loadings.

We conducted confirmatory factor analyses with the RSWBS items, treating the items as ordinal. A four-factor model fit the items well $\left(\chi^{2}(98)=432.3, \mathrm{CFI}=.965\right.$, TLI $=.957$, RMSEA $=$ $.092,90 \%$ CI $[.083, .101]$, SRMR $=.055)$. See Table S2 for standardized factor loadings. A confirmatory bifactor model with four specific factors also fit the items well $\left(\chi^{2}(88)=377.9, \mathrm{CFI}=\right.$ $.970, \mathrm{TLI}=.958, \mathrm{RMSEA}=.090,90 \% \mathrm{CI}[.081, .100], \mathrm{SRMR}=.053)$.

\subsubsection{Associations between the RES and RSWBS and other measures}

See Table S5 for correlations between the RES and RSWBS and demographic variables. These correlations were similar to those in Study 1 and Study 2. Although the RES and personal income were significantly correlated in Study 2, this was not the case in Study 3-a finding that matches that of Study 1.

Table S7 displays the correlations between the RES and the RSWBS and other psychological constructs. Again, these correlations were very similar to those found in Studies 1 and 2, further confirming the finding that the RES is more closely associated than the RSWBS with agreeableness, conscientiousness, and subjective measures of well-being, and also further confirming the association of both of our new measures of well-being with open-mindedness.

Most of the results were as expected. Both the RES and the RSWBS correlated with valuing stimulation and achievement, and the RSWBS was associated with self-direction. The RES but not the RSWBS was associated with valuing universalism, and the RSWBS but not the RES was correlated with valuing power and hedonism. The RES was associated with valuing benevolence but, contrary to expectations, the RSWBS was also associated with valuing benevolence. Other reported associations with values were exploratory.

\section{Discussion}

In three studies, we developed and validated two measures of well-being focused on the attainment of eudaimonic and external goods: the Riverside Eudaimonia Scale and the Rich \& Sexy Well-Being Scale. These measures were specifically designed to capture self-reported achievement, in contrast with the measures of subjective well-being used in most psychological research on well-being.

\subsection{Riverside Eudaimonia Scale}

The RES had favorable psychometric properties with just five items. Notably, a one-factor model fit well. In addition, the measure displayed acceptable reliability, in terms of both internal consistency and test-retest correlation.

We believe the RES has content validity, as it aligns with philosophical conceptions of eudaimonia. In addition, we provide evidence of the construct validity of the RES by correlating it with measures with which we would expect it to correlate. The RES was positively associated 
with education level and being in a relationship, whereas correlations between the RES and gender, age, and income were positive, as one might expect, but less consistent. The RES correlated with other well-being measures, but these correlations were low enough to suggest that we were measuring a different construct. The RES showed disattenuated correlations with the Psychological Well-Being Scale of approximately .9, suggesting that it is not unreasonable to interpret the Psychological Well-Being Scale as a measure of eudaimonia, although more subjectively conceived, given the content of the items. The RES was moderately correlated with each Big Five trait, matching previous correlational research linking well-being and the Big Five. However, the RES correlated more strongly with open-mindedness than other well-being measures typically correlate with this trait (Steel et al., 2008). Plausibly, agreeing that one is "inventive, [finding] clever ways to do things" and "original, [coming] up with new ideas" (Big Five open-mindedness) are likely to be related to describing one's life as full of learning, change, and growth, and that one has realized one's creative, artistic, intellectual, or athletic potential (RES).

Lastly, Study 2 found a significant and moderate positive correlation between the RES and socially desirable responding, which was replicated in Study 3. Measures of well-being are typically correlated with socially desirable responding, and it is unsurprising that the RES would be similarly impacted.

\subsection{Rich \& Sexy Well-Being Scale}

Our new RSWBS also showed favorable psychometric properties. Although we initially expected a five-factor model to provide the most interpretable factors, a four-factor model seemed most appropriate and fit the model well, with facets for wealth, physical beauty, social status, and sex life. The RSWBS and its facets showed high internal consistency and high test-retest correlations.

Predictably, the RSWBS was positively associated with education level, being in a relationship, and income. However, it was not significantly correlated with age or gender. The RSWBS was positively correlated with other well-being measures, but as expected, the correlations were lower than the correlations between eudaimonia and the same measures. The positive relationship among subjective measures of well-being, eudaimonic flourishing, and attainment of goods described in the RSWBS fits well with Bishop's (2015) "inclusive approach" to well-being, which suggests well-being involves positive causal networks containing selfreinforcing elements. Subjective well-being and the attainment of eudaimonic and noneudaimonic goods all tend to relate positively: Finding meaningful work in which you are successful (eudaimonic well-being) can enhance mood (subjective well-being) and income (rich \& sexy well-being), which can then open further opportunities for the attainment of subjective and objective well-being in a positive (virtuous) cycle. Conversely, losing one's job can have downstream consequences on well-being in a negative (vicious) cycle. Similarly, a good sex life, loving relationships, financial security, and life satisfaction might all form a positive causal network in a typical well-functioning marriage.

The RSWBS showed small positive correlations with Machiavellianism and narcissism. We speculate that the correlations are positive due to a relationship between Machiavellianism, narcissism, and the valuing of the goods on the rich \& sexy list, but low due to the fact that seeking does not imply getting, and excessive Machiavellianism or narcissism might in the long run interfere with obtaining wealth, social status, and sex (Furnham et al., 2013). It is also unsurprising that narcissists would rate themselves favorably with regard to physical beauty. 


\subsection{Limitations and future directions}

Our measures employ self-report, which is not the ideal way to assess objective aspects of wellbeing. For example, agreement with "I am wealthy" or "I am more attractive than most people my age" on the RSWBS might reflect self-confidence as much as it reflects verifiable wealth or conventional physical attractiveness. Agreement with "I know what is really important in life" might reflect sophomoric self-assurance rather than actual practical wisdom. Despite these possible limitations, subjective measures of objective goods are often accepted as adequately valid. For example, researchers frequently ask students for their grade point averages instead of requesting their transcripts.

Future studies might disentangle self-report from objective attainment by using non-selfreport measures, such as peer ratings of physical beauty or practical wisdom, or objective measures of wealth or intellectual or athletic attainment. Outside of verifiable self-insight in these domains, there may be interesting predictive value in self-perceptions about such matters.

As previously noted, our lists of eudaimonic and non-eudaimonic goods are incomplete. We wanted two measures that would capture a sharp distinction between "eudaimonic" goods characteristic of distinctly human flourishing valued by philosophers and "rich \& sexy" goods that many people value highly despite being downplayed in philosophical traditions. Other goods, like health, security, and autonomy, do not fall clearly on either side, while also overlapping with "quality of life" measures in public health policy (Cooke et al., 2016). Moral attainment is also absent from our lists, despite its prominence in philosophical eudaimonic accounts - in part because we doubt the validity of self-reports of general moral attainment (Schwitzgebel, 2019; Sun \& Goodwin, 2019) and in part because including it would suggest ethical attainment is not just ethically good but also partly directly constitutive of personal, prudential well-being. Finally, thorough eudaimonic lists often include subjective goods like pleasure, problematizing the subjective/objective distinction (Annas, 2011). Such goods were excluded to enhance the contrast between our measures and existing subjective measures. A complete measure of flourishing would require a complete list of objective goods that are properly weighted in the cultural context-a task far more ambitious than we attempt here. (For thoughts on how to get closer to this goal, see Alexandrova, 2018; Nussbaum, 2011; Seligman, 2011.)

Finally, our studies recruited participants online-primarily White and from the UK and the U.S. Paid online participants might be expected to have different attitudes toward work and money than the general population (Kaufmann et al., 2011). Also, given cultural differences in self-reported values (Schwartz, 1994), members of collectivist cultures may show lower correlations between rich \& sexy well-being and other types of well-being; they may also prioritize social well-being over individual well-being. Furthermore, for people in relatively less wealthy nations, the pursuit of wealth may be positively related to well-being when such pursuit enables financial security and the satisfaction of basic needs (Ingrid et al., 2009). This possibility holds particular relevance for the RSWBS, which we acknowledge may represent particularly rich, industrialized, and Western outlooks on non-eudaimonic well-being. Further work is needed in validating this scale cross-culturally.

\subsection{Concluding remarks}

Apart from subjective well-being, a growing body of research is focused on eudaimonia, which refers to the attainment of goods related to human excellence. The Riverside Eudaimonia Scale was designed to capture eudaimonia, with just five items, in a way that is informed by philosophical work on human flourishing. In addition, we developed a new measure of non- 
eudaimonic well-being: the Rich \& Sexy Well-Being Scale. Both measures appear reliable and valid, although the accuracy of self-ratings remains a concern until self-reports can be checked against non-self-report measures.

Psychologists tend to favor subjective approaches to well-being. In contrast, many philosophical, literary, and popular traditions conceptualize well-being as a matter of attaining certain outward goods and living up to one's human potential. According to the latter approaches, attaining such goods might actually be constitutive of the good life. According to more subjective views, such attainments might simply correlate with well-being. We offer that the good life consists of positive subjective evaluations of one's life and current state, healthy psychological functioning in key domains, and attainment of life-enriching goods, whether those are characteristic of expressing one's full human potential (eudaimonic) or perhaps are part of baser human indulgences (non-eudaimonic). Ultimately, fruitful interdisciplinary discourse requires good self-report measures of all components of what it means to be well.

\section{Conflict of interest statement}

The authors declared no potential conflicts of interest with respect to the research, authorship, and/or publication of this article.

\section{Funding Statement}

This research was supported by a grant from Happiness and Well-Being: Integrating Research Across the Disciplines, Saint Louis University.

\section{Data Availability Statement}

Data is available upon request via the corresponding author.

\section{Authors}

Seth Margolis

University of California, Riverside

Eric Schwitzgebel

University of California, Riverside

Daniel J. Ozer

University of California, Riverside

Ramona L. Martinez

University of California, Riverside

Sonja Lyubomirsky

University of California, Riverside

Sonja.lyubomirsky@ucr.edu

\section{Publishing Timeline}

Received 29 January 2021

Revised version received 12 September 2021

Accepted 8 November 2021

Published 31 January 2022 


\section{References}

Abbott, R. A., Ploubidis, G. B., Huppert, F. A., Kuh, D., Wadsworth, M. E., \& Croudace, T. J. (2006). Psychometric evaluation and predictive validity of Ryff's psychological well-being items in a UK birth cohort sample of women. Health and Quality of Life Outcomes, 4, 76. https://doi.org/10.1186/14777525-4-76

Aknin, L. B., Dunn, E. W., \& Norton, M. I. (2012). Happiness runs in a circular motion: Evidence for a positive feedback loop between prosocial spending and happiness. Journal of Happiness Studies, 13(2), 347-355. https://doi.org/10.1007/s10902-011-9267-5

Aknin, L. B., Norton, M. I., \& Dunn, E. W. (2009). From wealth to well-being? Money matters, but less than people think. The Journal of Positive Psychology, 4(6), 523-527.

https://doi.org/10.1080/17439760903271421

Alexandrova, A. (2017). A philosophy for the science of well-being. Oxford: Oxford University Press.

Annas, J. (2011). Intelligent virtue. New York: Oxford University Press.

Aristotle (2002). Nicomachean ethics. (C. J. Rowe \& S. Broadie, Trans.). New York: Oxford University Press. (Original work published in $4^{\text {th }}$ century BCE)

Belk, R. W. (1984). Three scales to measure constructs related to materialism: Reliability, validity, and relationships to measures of happiness. Advances in Consumer Research, 11, 291-297. Retrieved from https://www.acrwebsite.org/volumes/6260/volumes/v11/NA-11Belk

Bishop, M. A. (2015). The good life: Unifying the philosophy and psychology of well-being. New York: Oxford University Press.

Brdar, I., Majda, R., \& Dubravka, M. (2009). Life goals and well-being: Are extrinsic aspirations always detrimental to well-being? Psihologijske Teme, 18(2), 317-334.

Cooke, P. J., Melchert, T. P., \& Connor, K. (2016). Measuring well-being: A review of instruments. The Counseling Psychologist, 44, 730-757. https://doi.org/ 10.1177/0011000016633507

Csikszentmihalyi, M. (1999). If we are so rich, why aren't we happy? American Psychologist, 54(10), 821827. https://doi.org/10.1037/0003-066X.54.10.821

Darwall, S. L. (2002). Virtue ethics. Hoboken, NJ: Wiley-Blackwell.

De Bruin, G. P., \& Du Plessis, G. A. (2015). Bifactor analysis of the Mental Health Continuum-Short Form (MHC-SF). Psychological Reports, 116, 438-446. https://doi.org/10.2466/03.02.PR0.116k20w6

Deci, E. L., \& Ryan, R. M. (2008). Hedonia, eudaimonia, and well-being: An introduction. Journal of Happiness Studies, 9(1), 1-11. https://doi.org/10.1007/s10902-006-9018-1

Diener, E. (1984). Subjective well-being. Psychological Bulletin, 95, 542-575. https://doi.org/10.1037/00332909.95.3.542

Diener, E., \& Biswas-Diener, R. (2002). Will money increase subjective well-being? Social Indicators Research, 57(2), 119-169. https://doi.org/10.1023/A:1014411319119

Diener, E., \& Emmons, R. A. (1984). The independence of positive and negative affect. Journal of Personality and Social Psychology, 47, 1105-1117. https://doi.org/10.1037/0022-3514.47.5.1105

Diener, E., \& Seligman, M. E. P. (2004). Beyond money: Toward an Economy of well-being. Psychological Science in the Public Interest, 5(1), 1-31. https://doi.org/10.1111/j.0963-7214.2004.00501001.x

Diener, E., Lucas, R. E., \& Oishi, S. (2018). Advances and open questions in the science of subjective wellbeing. Collabra: Psychology, 4, 15. https://doi.org/10.1525/collabra.115

Diener, E., Wirtz, D., Tov, W., Kim-Prieto, C., Choi, D., Oishi, S., \& Biswas-Diener, R. (2010). New wellbeing measures: Short scales to assess flourishing and positive and negative feelings. Social Indicators Research, 97, 143-156. https://doi.org/10.1007/s11205-009-9493-y

Fletcher, G. (2013). A fresh start for the objective-list theory of well-being. Utilitas, 25, 206-220. https://doi.org/10.1017/S0953820812000453

Franken, K., Lamers, S. M., Ten Klooster, P. M., Bohlmeijer, E. T., \& Westerhof, G. J. (2018). Validation of the Mental Health Continuum-Short Form and the dual continua model of well-being and psychopathology in an adult mental health setting. Journal of Clinical Psychology, 74, 2187-2202. https://doi.org/10.1002/jclp.22659

Furnham, A., Richards, S. C., \& Paulhus, D. L. (2013). The Dark Triad of personality: A 10 year review. Social and Personality Psychology Compass, 7, 199-216. https://doi.org/10.1111/spc3.12018 
Gasper, D. (2010). Understanding the diversity of conceptions of well-being and quality of life. Journal of Socio-Economics, 39, 351-360. https://doi.org/10.1016/j.socec.2009.11.006

Griffin, J. (1986). Well-being: Its meaning, measurement and moral importance. Oxford: Clarendon Press.

Hart, C. M., Ritchie, T. D., Hepper, E. G., \& Gebauer, J. E. (2015). The Balanced Inventory of Desirable Responding Short Form (BIDR-16). Sage Open, 5, 1-9. https://doi.org/10.1177/2158244015621113

Haybron, D. M. (2008). Happiness, the self and human flourishing. Utilitas, 20, 21-49. https://doi.org/10.1017/S0953820807002889

Hobbes, T. (1651/1996). Leviathan (R. Tuck, Ed.). Cambridge: Cambridge University Press.

Homer ( $8^{\text {th }}$ C. BCE/1951). The Iliad, (R. Lattimore, Trans.). Chicago: University of Chicago Press. (Original work published in 8 th century BCE).

Hurka, T. (2011). The best things in life. Oxford: Oxford University Press.

Jonason, P. K., \& Webster, G. D. (2010). The Dirty Dozen: A concise measure of the dark triad. Psychological Assessment, 22, 420-432. https://doi.org/10.1037/a0019265

Jovanović, V. (2015). Structural validity of the Mental Health Continuum-Short Form: The bifactor model of emotional, social and psychological well-being. Personality and Individual Differences, 75, 154-159. https://doi.org/10.1016/j.paid.2014.11.026

Kafka, G. J., \& Kozma, A. (2002). The construct validity of Ryff's scales of psychological well-being (SPWB) and their relationship to measures of subjective well-being. Social Indicators Research, 57, 171190. https://doi.org/10.1023/A:1014451725204

Kasser, T., \& Ryan, R. M. (1996). Further examining the American dream: Differential correlates of intrinsic and extrinsic goals. Personality and Social Psychology Bulletin, 22(3), 280-287. https://doi.org/10.1177/0146167296223006

Kaufmann, N., Schulze, T., \& Veit, D. (2011). More than fun and money. Worker Motivation in Crowdsourcing - A Study on Mechanical Turk. Americas' Conference on Information Systems 2011 Proceedings. 340.

Kenny, D. A., Kaniskan, B., \& McCoach, D. B. (2015). The performance of RMSEA in models with small degrees of freedom. Sociological Methods \& Research, 44, 486-507. https://doi.org/10.1177/0049124114543236

Keyes, C. L. M. (2002). The mental health continuum: From languishing to flourishing in life. Journal of Health and Social Behavior, 43, 207-222. https://doi.org/10.2307/3090197

Keyes, C. L. M., Shmotkin, D., \& Ryff, C. D. (2002). Optimizing well-being: The empirical encounter of two traditions. Journal of Personality and Social Psychology, 82(6), 1007-1022. https://doi.org/10.1037/0022-3514.82.6.1007

Keyes, C. L. M., Wissing, M., Potgieter, J. P., Temane, M., Kruger, A., \& Van Rooy, S. (2008). Evaluation of the mental health continuum-short form (MHC-SF) in Setswana-speaking South Africans. Clinical Psychology E Psychotherapy, 15, 181-192. https://doi.org/10.1002/cpp.572

King, L. A., \& Napa, C. K. (1998). What makes a life good? Journal of Personality and Social Psychology, 75(1), 156-165. https://doi.org/10.1037/0022-3514.75.1.156

Knoblock, J., \& Riegel, J. K. (2000). “Yangist” chapters. In The annals of Lü Buwei. Stanford, CA: Stanford University Press. (Original work published in 3rd century BCE)

Kraut, R. (2007). What is good and why. Cambridge, MA: Harvard.

Lamers, S. M., Westerhof, G. J., Bohlmeijer, E. T., ten Klooster, P. M., \& Keyes, C. L. (2011). Evaluating the psychometric properties of the Mental Health Continuum-Short Form (MHC-SF). Journal of Clinical Psychology, 67, 99-110. https://doi.org/10.1002/jclp.20741

Little, R. J. (1988). Missing-data adjustments in large surveys. Journal of Business \& Economic Statistics, 6, 287-296. https://doi.org/10.1080/07350015.1988.10509663

Lyubomirsky, S., \& Lepper, H. S. (1999). A measure of subjective happiness: Preliminary reliability and construct validation. Social Indicators Research, 46, 137-155. https://doi.org/10.1023/A:1006824100041

Margolis, S., Schwitzgebel, E., Ozer, D. J., \& Lyubomirsky, S. (2018). A new measure of life satisfaction: The Riverside Life Satisfaction Scale. Journal of Personality Assessment. Advance online publication. https://doi.org/10.1080/00223891.2018.1464457 
Margolis, S., Schwitzgebel, E., Ozer, D. J., \& Lyubomirsky, S. (2019). Empirical relationships among five types of well-being. Manuscript submitted for publication.

McDonald, R. P. (1999). Test theory: A unified Treatment. Mahwah, NJ: Lawrence Erlbaum Associates.

Moons, P., Budts, W., \& De Geest, S. (2006). Critique on the conceptualisation of quality of life: A review and evaluation of different conceptual approaches. International Journal of Nursing Studies, 43, 891901. https://doi.org/10.1016/j.ijnurstu.2006.03.015

Nussbaum, M. C. (2011). Creating capabilities. Cambridge, MA: Harvard University Press.

Proctor C., \& Tweed R. (2016). Measuring eudaimonic well-being. In J. Vittersø (Ed.), Handbook of eudaimonic well-being (pp. 277-294). New York: Springer.

Phillips, J. T., Jacobs, S. D., \& Styles, D. (1997). Money, Power, \& Respect [Recorded by The LOX]. On Money, Power, \& Respect [CD]. New York: Bad Boy Records.

Rice, C. M. (2013). Defending the objective list theory of well-being. Ratio, 26, 196-211. https://doi.org/10.1111/rati.12007

Rubin, D. B. (1986). Statistical matching using file concatenation with adjusted weights and multiple imputations. Journal of Business \& Economic Statistics, 4, 87-94. https://doi.org/10.1080/07350015.1986.10509497

Rubin, M. (2016). The Perceived Awareness of the Research Hypothesis Scale: Assessing the influence of demand characteristics. Figshare. https://doi.org/10.6084/m9.figshare.4315778

Ryan, R. M., Curren, R. R., \& Deci, E. L. (2013). What humans need: Flourishing in Aristotelian philosophy and self-determination theory. In A. S. Waterman (Ed.), The best within us (pp. 57-75). Washington, DC: American Psychological Association.

Ryan, R. M., \& Deci, E. L. (2000). Self-determination theory and the facilitation of intrinsic motivation, social development, and well-being. American Psychologist, 55(1), 68-78. https://doi.org/10.1037/0003066X.55.1.68

Ryan, R. M., \& Deci, E. L. (2001). On happiness and human potentials: A review of research on hedonic and eudaimonic well-being. Annual Review of Psychology, 52, 141-166. https://doi.org/10.1146/annurev.psych.52.1.141

Ryan, R. M., Huta, V., \& Deci, E. L. (2008). Living well: A self-determination theory perspective on eudaimonia. Journal of Happiness Studies, 9, 139-170. https://doi.org/10.1007/s10902-006-9023-4

Ryff, C. D. (1989). Happiness is everything, or is it? Explorations on the meaning of psychological wellbeing. Journal of Personality and Social Psychology, 57, 1069-1081. https://doi.org/10.1037/00223514.57.6.1069

Ryff, C. D. (2014). Psychological well-being revisited: Advances in the science and practice of eudaimonia. Psychotherapy and Psychosomatics, 83, 10-28. https://doi.org/10.1159/000353263

Ryff, C. D., \& Keyes, C. L. M. (1995). The structure of psychological well-being revisited. Journal of Personality and Social Psychology, 69, 719-727. https://doi.org/10.1037/0022-3514.69.4.719

Schenker, N., \& Taylor, J. M. (1996). Partially parametric techniques for multiple imputation. Computational Statistics \& Data Analysis, 22, 425-446. https://doi.org/10.1016/0167-9473(95)00057-7

Schopenhauer, A. (1851/2007). Studies in pessimism (T. B. Saunders, Trans.). New York: Cosimo.

Schutte, L., Wissing, M. P., \& Khumalo, I. P. (2013). Further validation of the questionnaire for eudaimonic well-being (QEWB). Psychology of Well-Being: Theory, Research and Practice, 3, 1-22. https://doi.org/10.1186/2211-1522-3-3

Schwartz, S. H. (1992). Universals in the content and structure of values: Theoretical advances and empirical tests in 20 countries. Advances in Experimental Social Psychology, 25, 1-65. https://doi.org/10.1016/S0065-2601(08)60281-6

Schwartz, S. H. (1994). Beyond individualism/collectivism: New cultural dimensions of values. In U. Kim, H. C. Triandis, Ç. Kâğitçibaşi, S.-C. Choi, \& G. Yoon (Eds.), Cross-cultural research and methodology series, Vol. 18. Individualism and collectivism: Theory, method, and applications (pp. 85-119). Thousand Oaks, CA: Sage Publications.

Schwitzgebel, E. (2007). Human nature and moral education in Mencius, Xunzi, Hobbes, and Rousseau. Journal of the History of Philosophy, 24, 147-168. Retrieved from https://www.jstor.org/stable/27745086 Schwitzgebel. E. (2019). A theory of jerks and other philosophical misadventures. Cambridge, MA: MIT Press. 
Seligman, M.E. (2011). Flourish: A visionary new understanding of happiness and well-being. New York: Free Press.

Sheldon, K. M. (2018). Understanding the good life: Eudaimonic living involves well-doing, not wellbeing. In J. P. Forgas \& R. F. Baumeister (Eds.), The social psychology of living well (pp. 116-136). New York: Psychology Press.

Sheldon, K. M., Ryan, R. M., Deci, E. L., \& Kasser, T. (2004). The independent effects of goal contents and motives on well-being: It's both what you pursue and why you pursue it. Personality and Social Psychology Bulletin, 30(4), 475-486. https://doi.org/10.1177/0146167203261883

Sher, G. (1997). Approximate justice: Studies in social, political, and legal philosophy. Lanham, MD: Rowman \& Littlefield Publishers.

Schönbrodt, F. D., \& Perugini, M. (2013). At what sample size do correlations stabilize? Journal of Research in Personality, 47, 609-612. https://doi.org/10.1016/j.jrp.2013.05.009

Soto, C. J., \& John, O. P. (2017a). The next Big Five Inventory (BFI-2): Developing and assessing a hierarchical model with 15 facets to enhance bandwidth, fidelity, and predictive power. Journal of Personality and Social Psychology, 113, 117-143. https://doi.org/10.1037/pspp0000096

Soto, C. J., \& John, O. P. (2017b). Short and extra-short forms of the Big Five Inventory-2: The BFI-2-S and BFI-2-XS. Journal of Research in Personality, 68, 69-81. https://doi.org/10.1016/j.jrp.2017.02.004

Staw, B. M., Sutton, R. I., \& Pelled, L. H. (1994). Employee positive emotion and favorable outcomes at the workplace. Organization Science, 5(1), 51-71. https://doi.org/10.1287/orsc.5.1.51

Steel, P., Schmidt, J., \& Shultz, J. (2008). Refining the relationship between personality and subjective well-being. Psychological Bulletin, 134, 138-161. https://doi.org/10.1037/0033-2909.134.1.138

Sun, J., \& Goodwin, G. (2019). Do people want to be more moral? Manuscript at https://psyarxiv.com/9gux6. van Dierendonck, D. (2004). The construct validity of Ryff's Scales of Psychological Well-Being and its extension with spiritual well-being. Personality and Individual Differences, 36, 629-643.

Waterman, A. S. (Ed.). (2013). The best within us: Positive psychology perspectives on eudaimonia. American Psychological Association.

Waterman, A. S., Schwartz, S. J., Zamboanga, B. L., Ravert, R. D., Williams, M. K., Bede Agocha, V., ... \& Donnellan, B. M. (2010). The Questionnaire for Eudaimonic Well-Being: Psychometric properties, demographic comparisons, and evidence of validity. The Journal of Positive Psychology, 5, 41-61. https://doi.org/10.1080/17439760903435208

Xunzi (3rd c. BCE/2014). Xunzi: The complete text (E. Hutton, Trans.). Princeton, NJ: Princeton University Press. 